\title{
Management of hepatitis B: A longitudinal national survey - impact of the Canadian Hepatitis B Consensus Guidelines
}

\author{
Paul Marotta MD FRCPC ${ }^{1}$, Kurt Lucas BSc MSc Pharm²
}

P Marotta, K Lucas. Management of hepatitis B: A longitudinal national survey - impact of the Canadian Hepatitis B Consensus Guidelines. Can J Gastroenterol 2010;24(9):537-542.

BACKGROUND: The Canadian Association for the Study of the Liver, and The Association of Medical Microbiology and Infectious Diseases Canada, jointly developed the Canadian Chronic Hepatitis B (HBV) Consensus Guidelines to assist practitioners involved in the management of this complex disease. These guidelines were published in The Canadian Journal of Gastroenterology in June 2007 and distributed to all Canadian gastroenterologists and hepatologists.

OBJECTIVE: To assess the degree to which Canadian specialist physicians were able to incorporate the recommendations from the Canadian HBV Consensus Guidelines into their daily practice.

METHODS: A 30 min telephone survey probing the management strategies of 80 key HBV specialists was completed on three occasions, eight months apart, to longitudinally assess the impact of the Canadian HBV Consensus Guidelines on the management of HBV. The questionnaire detailed HBV practice patterns, the impact of the Canadian HBV Consensus Guidelines on clinical practice and HBV management.

RESULTS: The majority of specialists incorporated many of the published recommendations outlined in the Canadian HBV Consensus Guidelines into their daily practice for patients with HBV. However, because public drug coverage is a major hurdle in the management of $\mathrm{HBV}$, patients are provided markedly different HBV treatments depending on whether they have public or private drug insurance coverage.

CONCLUSIONS: The management of HBV is growing in complexity and continues to evolve rapidly. The Canadian HBV Consensus Guidelines have served as a valuable tool for many physicians in the management of HBV. However, effective treatment algorithms continue to be rendered irrelevant by restrictive drug coverage issues. Coverage for effective therapies and, therefore, management of HBV, differs widely across Canada depending on therapy reimbursement criteria rather than patient characteristics.

Key Words: Guidelines; Longitudinal; Management; Reimbursement
La prise en charge de l'hépatite B : Une enquête longitudinale nationale - Les répercussions des lignes directrices consensuelles sur la prise en charge de l'hépatite B au Canada

HISTORIQUE : L'Association canadienne pour l'étude du foie et l'Association pour la microbiologie médicale et l'infectiologie Canada ont conjointement rédigé Prise en charge de l'hépatite B chronique (VHB) : lignes directrices consensuelles canadiennes afin d'aider les praticiens qui participent à la prise en charge de cette maladie complexe. Ces lignes directrices ont été publiées dans Le Journal canadien de gastroentérologie en juin 2007 et distribuées à tous les gastroentérologues et hépatologues canadiens.

OBJECTIF : Évaluer le degré selon lequel les médecins spécialistes canadiens ont réussi à inclure les recommandations des lignes directrices consensuelles canadiennes sur le VHB dans leur pratique quotidienne.

MÉTHODOLOGIE : Les chercheurs ont procédé trois fois à un sondage téléphonique de 30 minutes pour explorer les stratégies thérapeutiques de 80 spécialistes clés du VHB, à huit mois d'intervalle, afin d'obtenir une évaluation longitudinale des répercussions des lignes directrices consensuelles canadiennes sur la prise en charge du VHB. Le questionnaire détaillait les modes de pratique du VHB, les répercussions des lignes directrices sur la pratique clinique et la prise en charge du VHB.

RÉSULTATS : La majorité des spécialistes ont intégré bon nombre des recommandations exposées dans les lignes directrices consensuelles canadiennes sur le VHB à leur pratique quotidienne auprès des patients atteints du VHB. Cependant, puisque le remboursement des médicaments sur ordonnance par le régime d'assurance public constitue un obstacle majeur dans la prise en charge du VHB, les patients reçoivent des traitements du VHB considérablement différents selon qu'ils sont dotés d'un régime d'assurance-médicaments public ou privé.

CONCLUSIONS : La prise en charge du VHB devient de plus en plus complexe et continue d'évoluer rapidement. Les lignes directrices consensuelles canadiennes sur le VHB constituent un outil précieux pour de nombreux médecins dans la prise en charge du VHB. Cependant, la pertinence des algorithmes de traitement efficaces continue d'être rendue caduque par des protections d'assurance-médicaments restrictives. La protection en vue de prodiguer des thérapies efficaces et, par conséquent, la prise en charge du VHB, varie énormément dans les régions du Canada selon des critères de remboursement des traitements plutôt que selon les caractéristiques des patients.

choices of agents that differ in cost, adverse effects, resistance profiles and efficacy. Currently, oral nucleoside and nucleotide agents and pegylated interferon-alpha $2 \mathrm{a}$ are the first-line choices for the management of HBV. While the therapeutic efficacy and safety of the therapies used to treat HBV are well known, selecting an agent for HBV therapy in Canada is more challenging because many patients do not have access to the most effective drugs due to formulary restrictions. For example, lamivudine (LAM) has largely fallen out of favour with speciality physicians due to its lack of efficacy and high rate of development of resistance; however, it is the agent most readily Oof chronic liver disease in Canada, with approximately tan ing cause of cancer (1). However, not all HBV-infected patients develop serious complications. The challenge in the management of chronic HBV is to identify individuals who are at a significant risk for the development of adverse consequences, and to offer this select group safe and effective treatment. Once an individual with HBV has been clinically assessed and deemed to require HBV therapy, there are a multitude of

${ }^{1}$ Liver Transplant Unit, London Health Sciences Centre, London, Ontario; ${ }^{2}$ Extension Marketing Inc, Ile Bizard, Quebec

Correspondence and reprints: Dr Paul Marotta, London Health Sciences Centre, 339 Windermere Road, London, Ontario N6A 5A5.

Telephone 519-685-8500, fax 519-663-3858, e-mail paul.marotta@lhsc.on.ca

Received for publication December 17, 2009. Accepted February 8, 2010 
available through provincial drug plans. Many Canadians have a significant public component to their drug coverage that typically limits therapeutic choices to the least expensive one, which, unfortunately, may also be the least potent and the one conferring the highest risk for development of resistance. Consequently, despite availability, adequate therapy is often not used in Canadian clinical practice due to public drug coverage restrictions.

Formulary complexity is a major barrier to treatment adoption because less experienced physicians often have difficulty with keeping up to date with the frequently changing restrictions of publicly funded programs and, as a result, are often reluctant to prescribe complex regimens. Additionally, there are structural barriers to treatment in Canada that result from the restrictive funding of laboratory tests and drug therapy, which currently prevent optimal treatment of those who need it.

The development, publication and dissemination of the Canadian HBV Consensus Guidelines (2) was envisioned to assist practising physicians with the associated complexities of HBV management. Close adherence to these guidelines would, in theory, improve the clinical management of HBV and potentially prevent many of the serious manifestations of this disease.

The primary objective of the present investigation was to assess the degree to which Canadian specialist physicians were able to incorporate the recommendations from the Canadian HBV Consensus Guidelines into their daily practice.

Longitudinal surveys have the ability to assess changes in clinical management of a disease over time. They are particularly valuable when they are conducted in conjunction with some form of intervention. In the current investigation, the impact of the Canadian HBV Consensus Guidelines acted as the intervention, and the series of surveys over time after the release of this document provides a picture of the evolving clinical management of HBV. Not only can this type of longitudinal survey detect improvements in management, it can also provide valuable information regarding barriers to the adoption of best-care practices.

\section{METHODS}

\section{Study sample}

A representative sample of 80 physicians who manage patients with HBV across Canada were involved in a two-year longitudinal survey. These physicians were necessarily members of the Canadian Association for the Study of the Liver (CASL) and/or the Canadian Association of Gastroenterology and, as part of their membership, received the published consensus document on HBV. Participating physicians were also required to manage a minimum of 12 new HBV referrals per year to qualify for inclusion in the present study. The participating physicians represented a stratified random sample based on geographical HBV population concentrations, with approximately $26 \%$, $50 \%, 20 \%$ and $4 \%$ of the physicians from Western Canada, Ontario, Quebec and Atlantic Canada, respectively. Approximately $45 \%$ of the sample were qualified as hepatologists, defined as specialist physicians who focus primarily on the treatment of hepatitis and/or liver disease, with the remaining $55 \%$ qualified as general gastroenterologists. Approximately $65 \%$ of the participating physicians were academic based and $35 \%$ were community based. Retention in the longitudinal study was high, with $84 \%$ completing all three phases of the investigation. The surveys questioned the same physicians over time, provided that they were available and still met the inclusion criteria (ie, had to see at least 12 new HBV patients per year); the latter is the main reason why the sample in phase I is slightly different than the sample in phase III.

\section{Survey methodology}

Identical 30 min telephone interviews were conducted at three distinct times, separated by approximately eight months, to assess the changes in HBV clinical management in the present cohort. The primary outcome was to evaluate whether the published Canadian HBV Consensus Guidelines had an impact on the clinical management of HBV and whether there was an increase in the adoption of the guidelines over time. The first telephone survey (phase I) was completed approximately six months following the publication and distribution of the guidelines, the second interview approximately 14 months following the publication (phase II) and the third and final interviews (phase III) occurred approximately 22 months following the publication of the guidelines. The questionnaire was administered by telephone by a third-party research firm specifically trained in the consistent administration of the survey.

\section{Survey design and testing}

The draft questionnaire was developed by prominent specialist physicians with significant expertise in the clinical management of HBV, and consisted of questions aimed at assessing the adoption of key clinical management strategies addressed in the Canadian HBV Consensus Guidelines publication. This particular questionnaire was further refined by a select group of CASL members and was translated into French by a professional translation service for use in French-speaking communities.

All participant responses were tabulated and reported for all assessed physicians $(n=80)$. To investigate differences among groups of participant physicians, the responses from groups identified as hepatologists, gastroenterologists or those specialists within the sample who, as identified by the survey, managed the greatest number of HBV patients (top 20), were compared.

\section{Analyses}

Each response was tabulated and statistical significance was determined using $95 \%$ CIs that did not cross unity or $\mathrm{P} \leq 0.05$. Differences among groups were assessed using $t$ tests or $\chi^{2}$ tests as appropriate.

\section{Respondents}

\section{RESULTS}

Eighty-four per cent of the initial cohort of physicians participated in all three phases of the study. Of the physicians not participating in all phases, $60 \%$ no longer met the criteria for participation (ie, did not manage a minimum of 12 new HBV patients per year), $20 \%$ no longer managed HBV, $10 \%$ could not participate because of scheduling issues and 10\% did not participate for unknown reasons. Regional representation (ie, percentage of physicians participating per region) was maintained over the duration of the study timeframe. Table 1 outlines the physician characteristics in greater detail. 
TABLE 1

Regional representation and physician characteristics

\begin{tabular}{|c|c|c|c|}
\hline & \multicolumn{3}{|c|}{ Investigation phase } \\
\hline & $\mathbf{I}$ & II & III \\
\hline Regional representation, \% & $\begin{array}{c}\text { Ontario 51, Western Canada 25, } \\
\text { Quebec 20, Atlantic Canada } 4\end{array}$ & $\begin{array}{c}\text { Ontario 50, Western Canada 27, } \\
\text { Quebec 19, Atlantic Canada } 4\end{array}$ & $\begin{array}{r}\text { Ontario 48, Western Canada } 27 \\
\text { Quebec 21, Atlantic Canada } 4\end{array}$ \\
\hline Hepatologists versus gastroenterologists, \% & 40 versus 60 & 45 versus 55 & 48 versus 52 \\
\hline Academic- versus community-based practice, $\%$ & 60 versus 40 & 65 versus 35 & 65 versus 35 \\
\hline
\end{tabular}

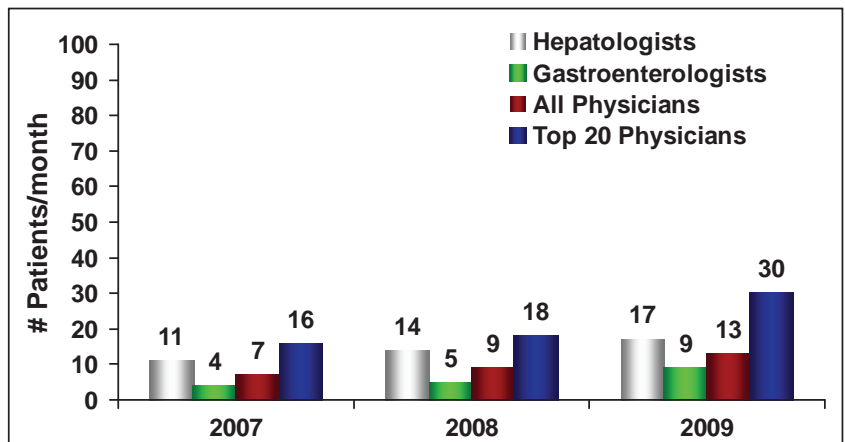

Figure 1) Number of new referrals for hepatitis B virus infection per month from 2007 to 2009

\section{Referral patterns and disease characteristics}

Fifty-seven per cent of physicians stated that HBV referrals increased steadily from 2007 to 2009 (trend analysis). The source of HBV referrals differed significantly according to specialty. Gastroenterologists were referred HBV patients primarily from general practitioners (86\%), while $12 \%$ were referred from other specialists. Hepatologists had approximately $71 \%$ of their referrals initiated by general practitioners and $25 \%$ from other specialists. Of interest, less than 5\% of HBV referrals to these cohorts were from public health organizations. Hepatologists are referred twice as many new HBV patients, and maintain care and monitoring of almost four times the number of HBV patients versus gastroenterologists (Figure 1).

When physicians were asked about the health state of their new HBV patients, 50\% were believed to possess 'active' disease (ie, potential candidates for treatment with elevated levels of HBV DNA and/or elevated alanine aminotransferase levels). Of the new referrals, $90 \%$ had never previously received HBV therapy (ie, treatment naive) and 10\% were treatment resistant or refractory; these findings were consistent over the course of the study (phases I to III). The majority (96\%) of treatmentresistant patients were LAM resistant (LAM-r); however, physicians reported that some patients (4\%) experienced the development of resistance to other agents including adefovir (ADF), entecavir (ETV) and telbivudine (TELB). These resistances were not commonly reported in 2007 (phase I), but became slightly more common in phases II and III. Of the HBV patients deemed to require pharmacological management, only $71 \%$ of the treatment-naive patients and $81 \%$ of the treatment-resistant/refractory patients were subsequently treated. The main reasons cited for not treating the remaining eligible patients included reimbursement (80\%) and affordability $(61 \%)$ barriers. Public plan reimbursement remains a major obstacle preventing the optimal care of HBV patients (Figure 2); this barrier did not change over the course of the longitudinal survey. Interestingly, hepatologists initiated therapy in $75 \%$ and $90 \%$ of the eligible treatment-naive patients

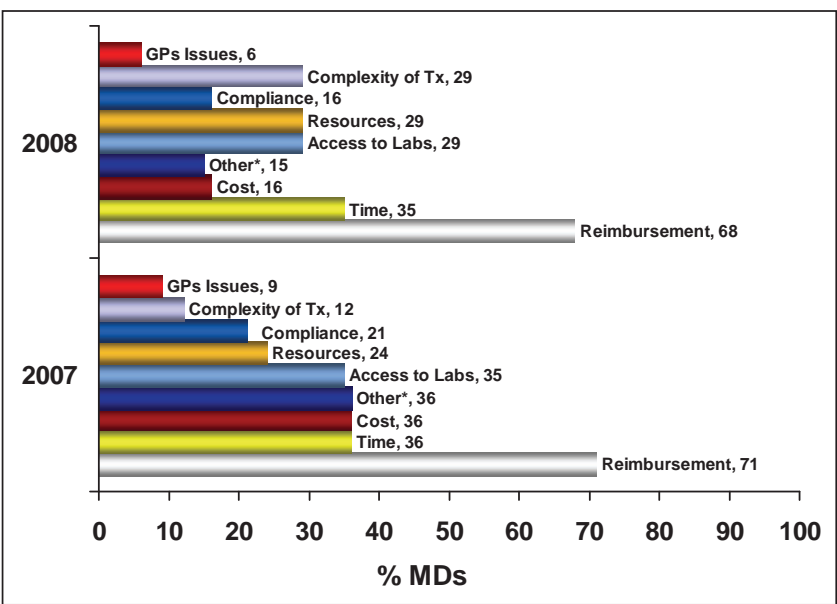

Figure 2) Major obstacles limiting the optimal care of chronic hepatitis B patients. *Other includes primarily language, labelling and administrative issues. GPs General practitioners; Labs Laboratories; MDs Physicians; Tx Treatment

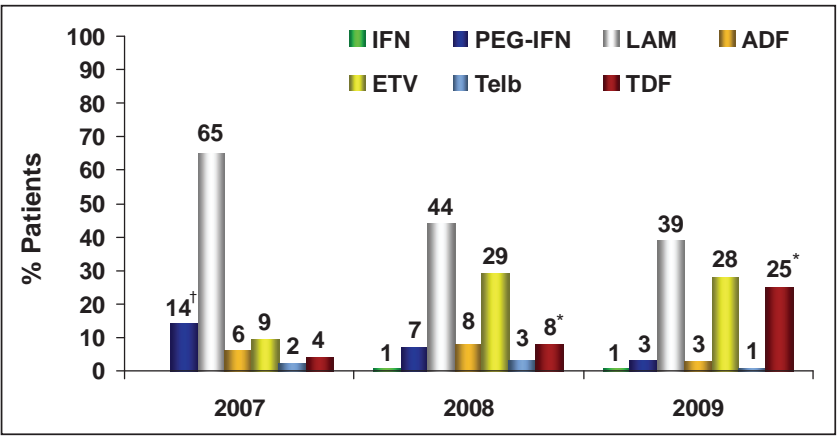

Figure 3) Treatment of treatment-naive chronic hepatitis B patients: Trend over time, 2007 to 2009. *P<0.05, 2008 versus 2009; ${ }^{\dagger}$ Includes standard interferon-alpha (IFN). ADF Adefovir; ETV Entecavir; LAM Lamivudine; Peg-IFN Pegylated interferon-alpha $2 a$ (Pegasys, Genentech USA); TDF Tenofovir; Telb Telbivudine

and treatment-resistant/refractory patients, respectively. This is in sharp contrast to the $68 \%$ and $64 \%$ of the eligible treatmentnaive and treatment-resistant/refractory patients, respectively, treated by general gastroenterologists.

\section{Treatment of treatment-naive $\mathrm{HBV}$ patients}

For the treatment of treatment-naive HBV patients (Figure 3), there was a $40 \%$ reduction in the use of LAM (phases I to III; 2007 to 2009: 65\%, 44\% and 39\%, respectively), a 211\% increase in ETV use (2007 to 2009: 9\%, 29\% and 28\%, respectively) and a $525 \%$ increase in tenofovir (TDF) use (2007 to 2009: $4 \%, 8 \%$ and 25\%, respectively) versus previous years. The various physician groups had similar prescribing patterns. 


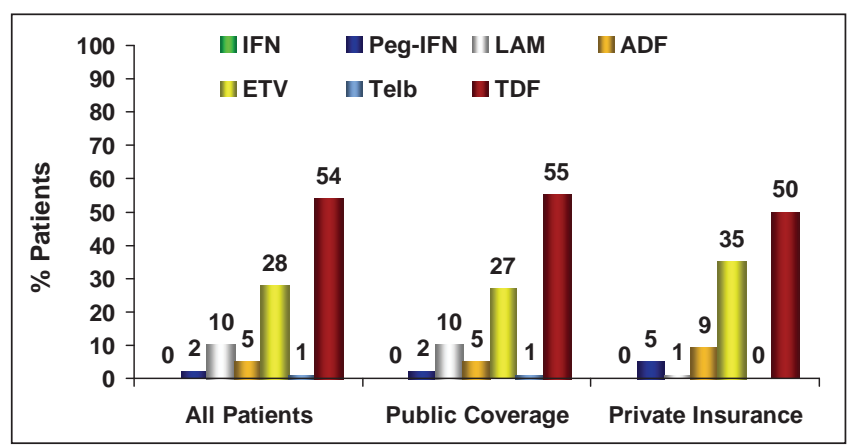

Figure 4) Treatment of treatment-naive chronic hepatitis B patients, phase III (2009) - Quebec: Public versus private insurance coverage. ADF Adefovir; ETV Entecavir; IFN Standard interferonalpha; LAM Lamiundine; Peg-IFN Pegylated interferon-alpha $2 a$ (Pegasys, Genentech, USA); TDF Tenofovir; Telb Telbivudine

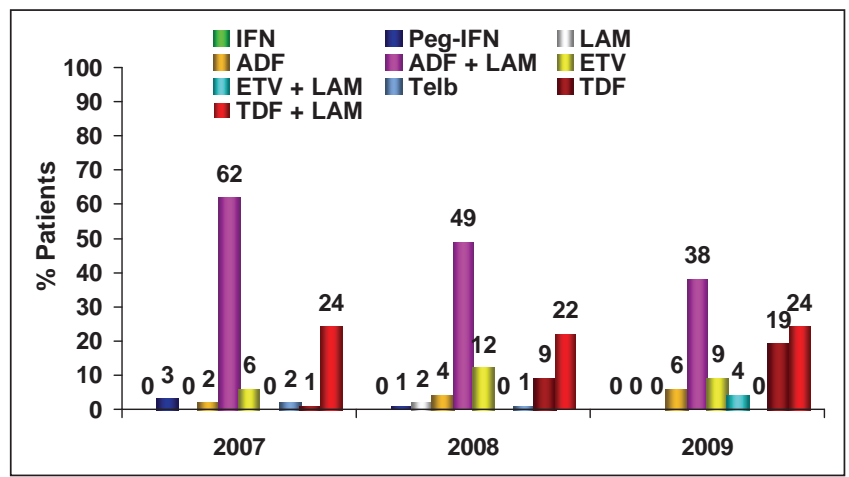

Figure 5) Treatment of lamivudine (LAM)-resistant chronic hepatitis B patients: Trend over time. ADF Adefovir; ETV Entecavir; IFN Standard interferon-alpha; Peg-IFN Pegylated interferonalpha $2 a$ (Pegasys, Genentech, USA); TDF Tenofovir; Telb Telbiuudine

The main differences in the management of HBV among physicians were observed on a regional level, with increasingly large regional differences evident over the time assessed (2009: phase III). In Ontario, treatment-naive patients with public funding generally receive LAM (77\%), whereas patients with private insurance preferentially receive either TDF $(51 \%)$ or ETV (32\%). In Quebec, both public and privately reimbursed patients receive primarily TDF ( $55 \%$ versus $50 \%$, respectively) followed by ETV (27\% versus 35\%, respectively) (Figure 4). In Western Canada, publicly funded patients primarily received LAM (56\%) followed by ETV (34\%), and privately funded patients received ETV (55\%) followed by TDF (22\%).

\section{Treatment of LAM-r HBV patients}

Regarding the treatment of LAM-r HBV patients (Figure 5), in 2009 , there was a $28 \%$ decrease in the use of ADF in combination with LAM (2007 to 2009: 62\%, 49\% and 38\%, respectively), a similar amount of TDF in combination with LAM used (2007 to 2009: 24\%, 22\% and 24\%, respectively) and a significant increase in the use of TDF monotherapy (2007 to 2009: $1 \%, 9 \%$ and $19 \%$, respectively) versus previous years. Interestingly, the use of TDF in combination with LAM is not outlined in the guidelines. Also noteworthy, some ETV use exists in this population - primarily from general gastroenterologists (16\% versus $2 \%$ among hepatologists). The use of ADF

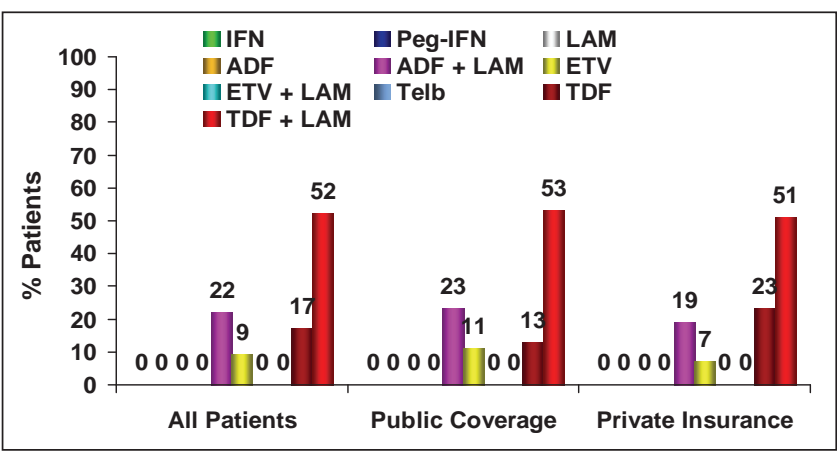

Figure 6) Treatment of lamivudine (LAM)-resistant chronic hepatitis B patients, phase III (2009) - Quebec: Public versus private insurance coverage. ADF Adefovir; ETV Entecavir; IFN Standard interferon-alpha; Peg-IFN Pegylated interferon-alpha 2 a (Pegasys, Genentech, USA); TDF Tenofovir; Telb Telbivudine

in combination with LAM is largely reimbursement driven. TDF monotherapy represents the largest growth segment in this population, with the main differences demonstrated on a regional level. In Ontario, LAM-r patients with public funding receive either ADF or TDF in combination with LAM (42\% versus $24 \%$, respectively), whereas patients with private insurance receive either TDF as monotherapy or in combination with LAM (40\% versus 32\%, respectively). In Quebec, both publicly and privately reimbursed LAM-r patients receive TDF plus LAM ( $53 \%$ versus $51 \%$, respectively) followed by TDF monotherapy (13\% versus $23 \%$, respectively) or ADF plus LAM (23\% versus $19 \%$, respectively) (Figure 6). In Western Canada, publicly funded patients primarily receive ADF plus LAM (75\%) and privately funded patients receive either ADF plus LAM (36\%), ETV (28\%), TDF plus LAM (19\%) or TDF (10\%).

\section{Treatment coverage}

Sixty-four per cent of the new HBV patients treated had public drug coverage only (Figures 7 and 8). Therapy for HBV patients varied significantly depending on whether HBV therapy coverage was publicly or privately funded (Figures 9 and 10). For example, in 2009, 58\% of treatment-naive HBV patients with public coverage were treated with LAM, whereas only $10 \%$ of treatment-naive HBV patients with private insurance were treated with LAM. HBV patients residing in Quebec were the exception because drug access was similar across all payers (Figures 4 and 6). Specifically in Quebec, the use of the various agents was very similar regardless of whether the patient had public or private reimbursement coverage. What changed over time was the shift from agents such as LAM and ADV to the newer, more potent agents ETV and TDF.

Approximately $10 \%$ of all treated patients receive some form of financial assistance from pharmaceutical companies that are involved in the manufacturing and marketing of specific HBV therapies. The presence of co-pay programs was cited as a factor influencing treatment choices by $80 \%$ of respondents and remained consistent from 2007 to 2009 (phases I to III).

Advantages and disadvantages of the various treatment options

When physicians were asked to name the key advantages of each of the various agents used to treat HBV (Table 2), 




Figure 7) Source (public, private or none) of drug reimbursement for chronic hepatitis B patients treated

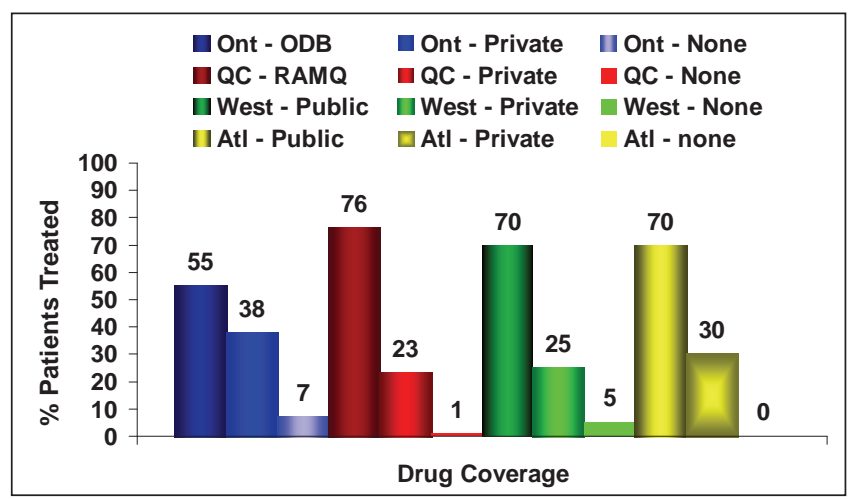

Figure 8) Source (public, private or none) of drug reimbursement according to region for chronic hepatitis B patients treated. Atl Atlantic Canada; ODB Ontario Drug Benefit Program; Ont Ontario; Private Private insurance; Public Public insurance; QC Quebec; RAMQ Régie de l'assurance maladie du Québec; West Western Canada

potency, efficacy and duration of treatment were the key components of differentiation. Similarly, when asked to outline the key disadvantages of each, cost, resistance profile and adverse events clearly divided the agents. ETV was consistently identified to be the most costly agent. With the exception of TDF and the interferons, all agents were cited as having the potential for patients to develop resistance. Adverse events were more commonly cited for the interferons and ADF.

Only the interferons were cited as having a short and finite duration of treatment (2007 to 2009: 59\%, 79\% and 65\% mention), whereas all of the oral agents were cited as most often requiring lifelong administration. The interferons were cited as being efficacious in a select subpopulation of patients (ie, young, hepatitis B e antigen positive, elevated alanine aminotransferase levels and moderate to low HBV DNA levels), but the associated adverse events were often mentioned as a barrier

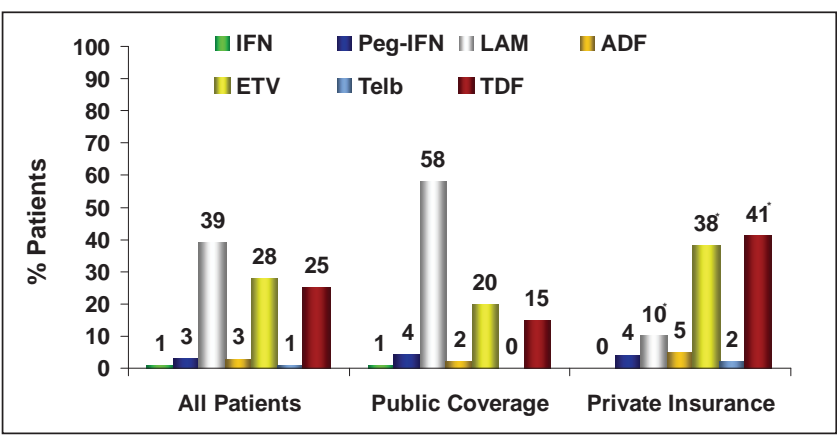

Figure 9) Treatment of treatment-naive chronic hepatitis $B$ patients, phase III (2009): Public versus private insurance coverage. $* P<0.05$. ADF Adefovir; ETV Entecavir; IFN Standard interferon-alpha; LAM Lamivudine; Peg-IFN Pegylated interferon-alpha $2 a$ (Pegasys, Genentech, USA); TDF Tenofovir; Telb Telbivudine

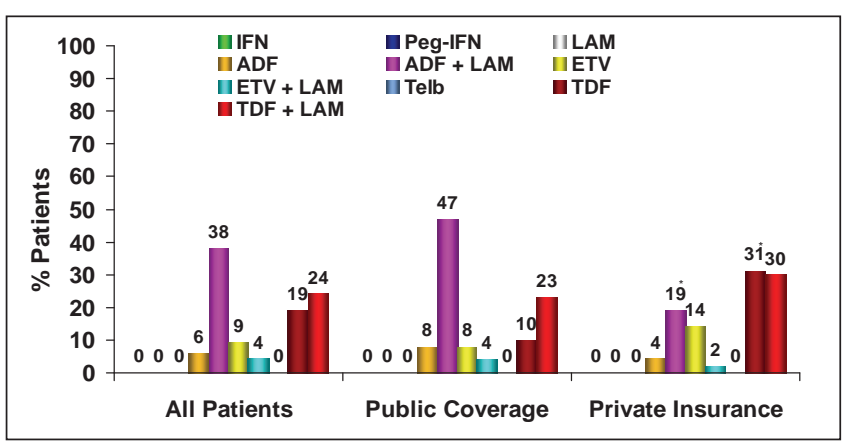

Figure 10) Treatment of lamivudine (LAM)-resistant chronic hepatitis B patients, phase III (2009): Public versus private insurance coverage. $* P<0.05$. ADF Adefovir; ETV Entecavir; IFN Standard interferon-alpha; Peg-IFN Pegylated interferon-alpha $2 a$ (Pegasys, Genentech, USA); TDF Tenofovir; Telb Telbivudine

to widespread use (2007 to 2009: 85\%, 88\% and 88\%). The key advantages to LAM were that it was well tolerated and less costly than the other agents used (2007 to 2009: 56\%, $45 \%$ and $53 \%$, and $45 \%, 55 \%$ and $65 \%$, respectively). The key disadvantage associated with the use of LAM was the high rate of resistance development (2007 to 2009: 93\%, 95\% and 98\% mention). The main advantage cited for ADF was that it was effective for the treatment of LAM-r patients (2007 to 2009: $52 \%, 51 \%$ and $55 \%)$ and the disadvantages were similar in terms of the percentage they were mentioned (2007 to 2009: range $23 \%$ to $43 \%$ ) and included the risk of adverse events, the elevated cost compared with the other HBV agents, its lack of potency and the increased risk of resistance development.

TABLE 2

Comparison of agents used to treat chronic hepatitis $B$

\begin{tabular}{|c|c|c|}
\hline Agent & Key advantages & Key disadvantages \\
\hline $\begin{array}{l}\text { Pegylated interferon-alpha } 2 \mathrm{a} / \\
\text { standard interferon-alpha }\end{array}$ & $\begin{array}{l}\text { Short and finite duration of treatment, efficacious in } \\
\text { select patient populations* }\end{array}$ & Adverse events \\
\hline Lamivudine & Safety profile, low cost & Potency, high resistance profile \\
\hline Adefovir & Efficacy in lamividine-resistant patients & Adverse events, high cost, potency, resistance profile \\
\hline Entecavir & High potency & High cost, high resistance profile \\
\hline Telbivudine & No overwhelming advantages & High resistance profile \\
\hline Tenofovir & High potency, low resistance profile & No overwhelming disadvantages \\
\hline
\end{tabular}

*Hepatitis B e antigen positive, younger than 40 years of age, elevated alanine aminotransferase levels, moderate to low hepatitis $B$ DNA levels 
ETV was found to be relatively potent, with a good resistance profile (2007 to 2009: $80 \%, 81 \%$ and $88 \%$, and $45 \%, 43 \%$ and $38 \%$, respectively). High cost was cited as the main disadvantage associated with ETV (2007 to 2009: 56\%, 63\% and $60 \%$, respectively); however, in 2009, $73 \%$ of physicians began mentioning the issue of cross-resistance with LAM. The key advantage cited for TELB was potency (2007 to 2009: 67\%, $31 \%$ and $25 \%$, respectively) and, by $2009,32 \%$ of physicians stated that TELB offered no distinct advantage over other existing agents. The key disadvantage associated with TELB was the development of resistance (2007 to 2009: 78\%, 75\% and $80 \%$, respectively). TDF was found to be highly potent and had a favourable resistance profile (2007 to 2009: 78\%, $75 \%$ and $80 \%$, and $51 \%, 35 \%$ and $61 \%$, respectively). The key disadvantages for TDF were similar in terms of the percentage they were mentioned, and included the elevated cost, the risk of adverse events and poor public reimbursement (2007 to 2009: range $20 \%$ to $38 \%$ ).

\section{DISCUSSION}

The management of HBV is complex and evolving rapidly with new findings in diagnosis and treatment. Diagnostic testing has improved dramatically over the past five years, as has the development of efficacious therapeutic agents. Case findings are increasing in Canada due to changing immigration patterns, increasing disease volumes and the evolving education of health professionals. Consensus guidelines provide the best evidence in a concise format and enable health care professionals to stay abreast of current best-practice management strategies; however, the impact of guidelines has not previously been studied among HBV specialty care providers. The present study reports the first longitudinal data from a large cohort of physicians treating HBV, with the expressed intent of evaluating the impact, uptake and adherence to Canadian HBV Consensus Guidelines. The present cohort was chosen from the membership of the CASL and the Canadian Association of Gastroenterology who are actively involved in treating chronic $\mathrm{HBV}$, and who received the guideline publication as members of affiliate organizations.

The primary strength of our stratified, random populationbased sample of physicians was that it represented a large, geographically diverse cohort, capturing a representative Canadian sample of treating physician specialists from both academicand community-based practices. Furthermore, retention in the 22 -month investigation was high, with $84 \%$ of the cohort completing all three phases of the investigation.
The Canadian HBV Consensus Guidelines were published and disseminated in June 2007. Initially, the recommendations were followed by $90 \%$ of the hepatologists and $100 \%$ of the general gastroenterologists who were interviewed. Over time, however, $85 \%$ of hepatologists and $93 \%$ of general gastroenterologists were following the guidelines, suggesting that the therapeutic arena had changed, as had the clinical experience of the respondents. The treatment of chronic HBV is complex and continues to evolve.

Several factors must be taken into account when selecting the most appropriate agent for an individual patient including treatment efficacy, safety, tolerability, resistance profiles, mode of administration and affordability. The agent selected for treatment should be chosen with consideration given to patient characteristics, stage of disease, affordability and patient preference - not solely as a result of restrictive public reimbursement. Finally, when selecting a nucleoside or nucleotide agent, it is important to note that an agent with both high potency and a high barrier to resistance would be expected to yield the best long-term results for the HBV-infected patient.

There are several variables to consider when managing HBV, for which The Canadian HBV Consensus Guidelines have provided several recommendations. Most of the physicians who participated in the present research stated that the consensus guidelines provided valuable guidance for the management of their patients with chronic HBV.

DISCLOSURE: Kurt Lucas operates an independent, private research company, and provides services for the pharmaceutical and medical device industries as well as nonprofit organizations (eg, The Ontario Rheumatology Association). He is not employed by any pharmaceutical company.

FUNDING: Funding for this project was provided through unrestricted research grants from several pharmaceutical companies, all of whom have products that were discussed as part of this research. These include Bristol-Myers Squibb, Gilead, Novartis and Roche Canada.

ACKNOWLEDGEMENTS: The authors thank Drs Karen Doucette, Kym Watts and Sam Lee for reviewing the draft questionnaire.

\section{REFERENCES}

1. Block TM, Mehta AS, Fimmel CJ, et al. Molecular viral oncology and hepatocellular carcinoma. Oncogene 2003;22:5093-107.

2. Sherman M, Shafran S, Burak K, et al. Management of chronic hepatitis B: Consensus guidelines. Can J Gastroenterol 2007;21(Suppl C):1-20. 


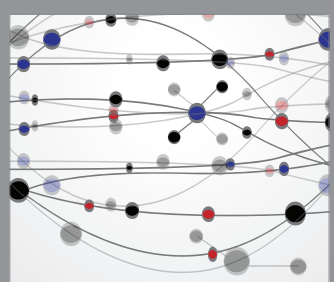

The Scientific World Journal
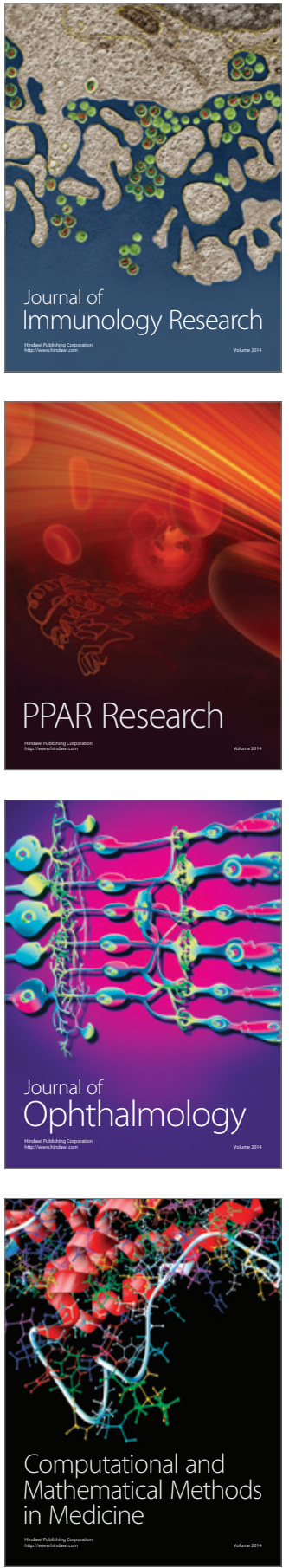

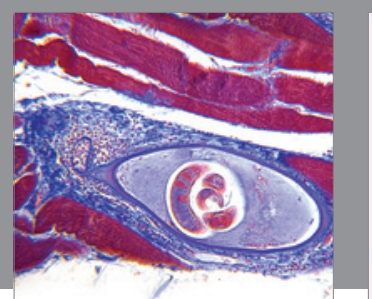

Gastroenterology Research and Practice

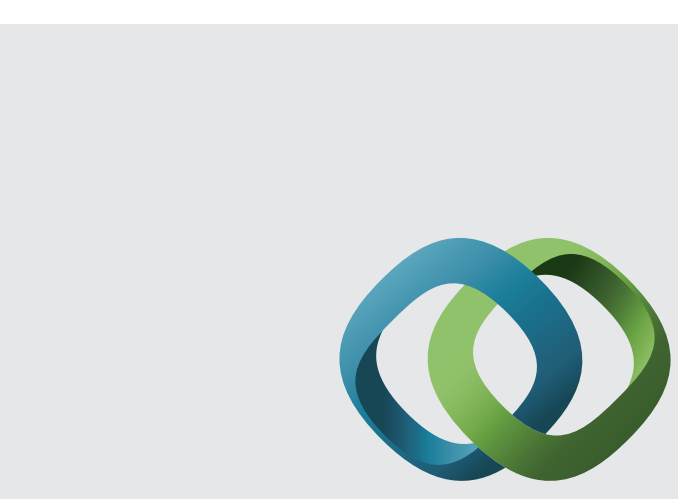

\section{Hindawi}

Submit your manuscripts at

http://www.hindawi.com
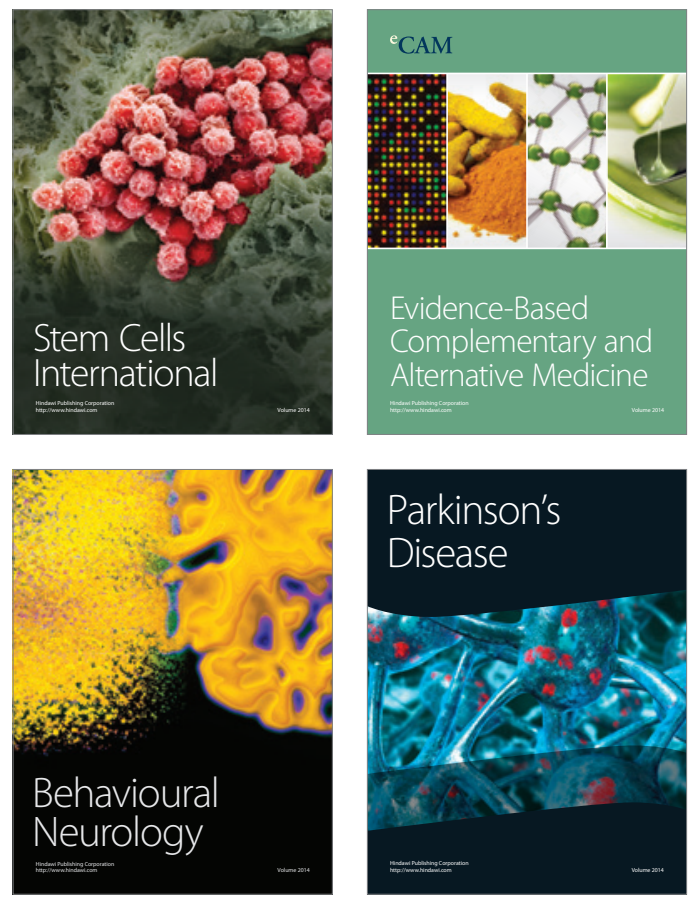
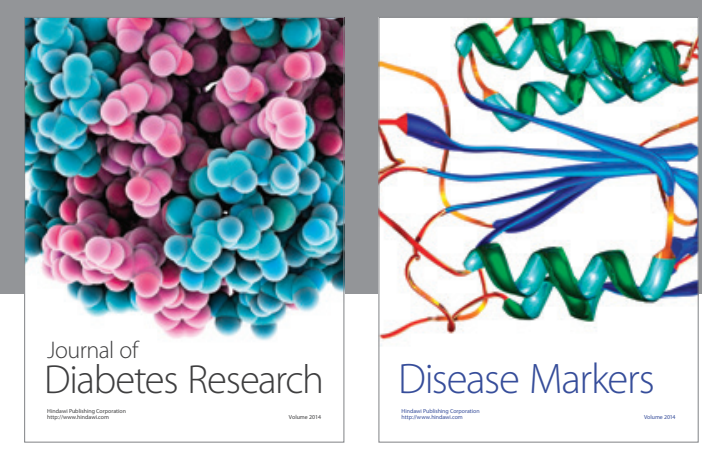

Disease Markers
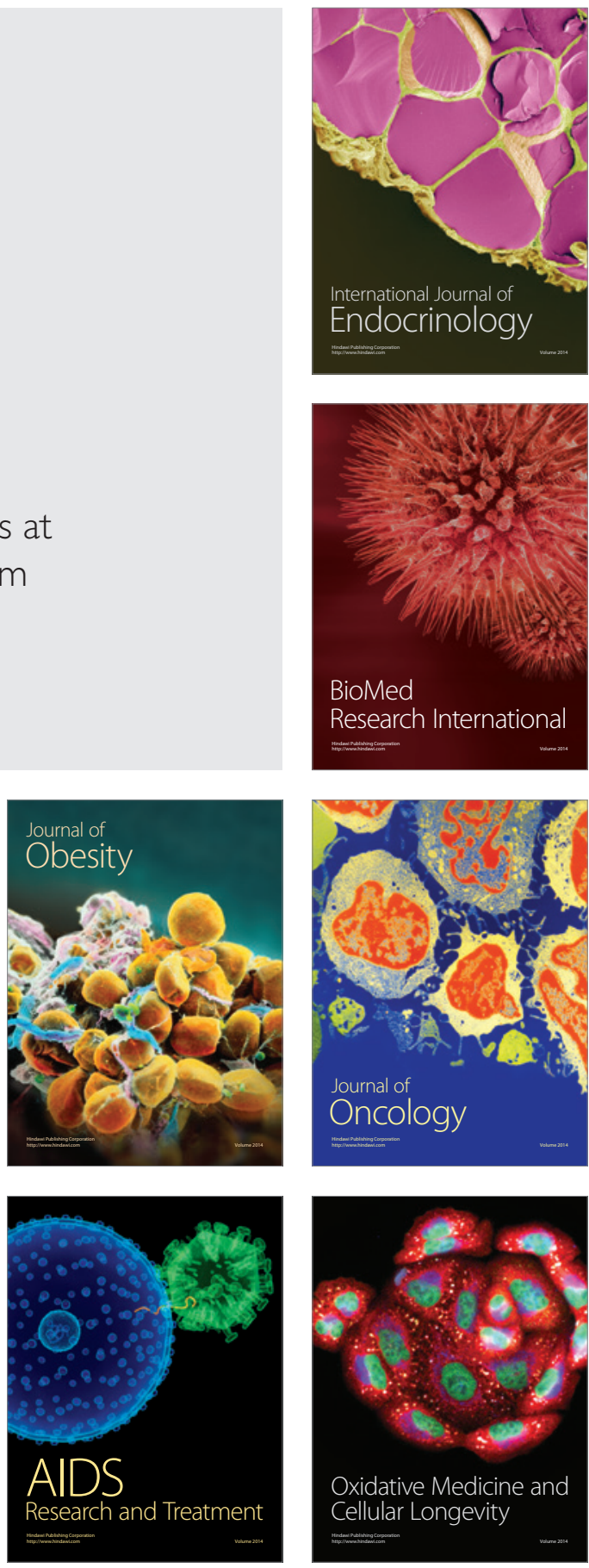